\section{Las ciencias sociales y el Estado nacional en México*}

Víctor Alarcón Olguín ${ }^{\S}$

El volumen que se comenta en esta oportunidad responde a la preocupación común de reflexionar en torno a las condiciones generales que han animado al desarrollo histórico y la institucionalización de las ciencias sociales en el contexto mexicano. El libro articula una serie de textos que pretenden revisar la evolución de las ciencias sociales desde la etapa prehispánica hasta el presente, situando sus hitos y actores más relevantes, lo que permite comprender cómo se fueron sistematizando los conocimientos y campos disciplinarios que dan fundamento a las profesiones y especialidades existentes en la actualidad. En este sentido, las contribuciones del texto residen en presentar una evaluación de las directrices y desempeños que han orientado las políticas institucionales aplicadas a las disciplinas sociales, tanto el ámbito nacional como regional, desde la perspectiva de estudios centrados en mostrar los desarrollos concretos de casos seleccionados.

¿Es una obligación sustantiva de las instituciones públicas como el Estado hacerse cargo del desarrollo científico o, bien, solo coadyuvar a facilitar las condiciones óptimas para que este pueda cumplirse desde la acción social o empresarial en el ámbito educativo y tecnológico? Sin duda, en cualquiera de los dos supuestos, la respuesta debe ser afirmativa. A partir de estas inquietudes, se provoca la discusión en torno a los momentos y los énfasis con que dicho proceso pueda atenderse conforme a las circunstancias propias de cada país.

Para el caso de América Latina, y de manera más particular en México, el impulso a las ciencias sociales como tal puede apenas remontarse hacia la mitad del siglo XX. Sin embargo, como se rescata en el ejercicio de reflexión introductoria de Contreras y Puga, hay elementos claros para rastrear las condiciones de la enseñanza y la sistematización de los conocimientos de orden social que se remontan hasta las civilizaciones prehispánicas. Esta exploración permite un abordaje de corte histórico-comparativo que nos lleva a valorar las dinámicas presentes en esas etapas iniciales de la organización nacional, y que paulatinamente permitieron desarrollar las bases de la acción pública institucional - plasmada en un proyecto en el cual se pudiera sustentar la orientación de consensos y aplicación de los conocimientos- para generar, así,
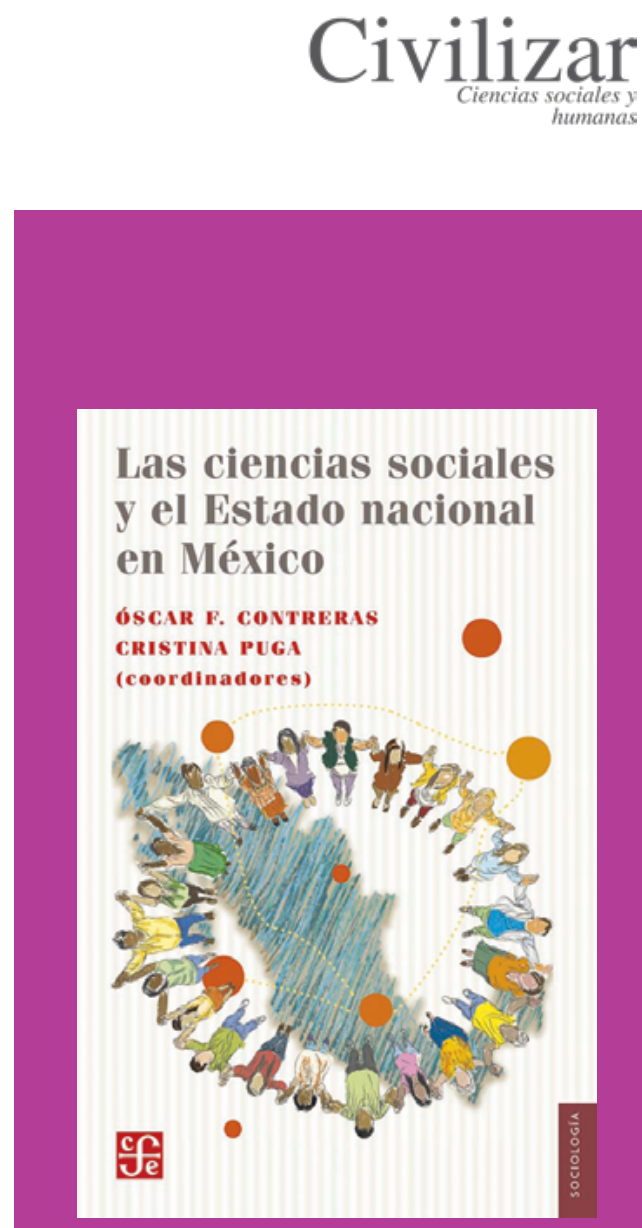

\section{Las ciencias sociales y el Estado nacional México}

Reseña

Título original:

Las ciencias sociales y el Estado

nacional en México

Autores: Óscar F. Contreras y

Cristina Puga (Coordinadores)

Año original de publicación: 2018

Edición: Primera (Colombia):

Páginas: 430

ISBN: 978-607-165800-5

Editorial: Fondo de Cultura

Económica

s Politólogo y Doctor en Estudios Sociales. Profesor-investigador Titular "C", Depar-

tamento de Sociología, Área de Procesos Políticos, Universidad Autónoma Metropolitana-Unidad Iztapalapa. Miembro del Sistema Nacional de Investigadores de México (Nivel II). Contacto: alar@xanum.uam.mx Licencia Creative Commons (i) $(5)$ S SinDerivar 4.0 Internacion BY NC ND (CC BY-NC-ND 4.0). 
políticas concretas en campos específicos. En este aspecto, las ciencias sociales siguen moviéndose dentro de un proceso que aún necesita consolidar lenguajes y redes profesionales tanto en la propia comunidad científica como entre quienes toman las decisiones de gobierno, a partir de las agendas temáticas que se han podido ir articulando en los diversos momentos históricos del desarrollo.

El volumen abre con un trabajo de Pablo Escalante Gonzalbo, quien se concentra en rescatar la contribución de los primeros humanistas de la etapa colonial a la comprensión de las sociedades prehispánicas y cómo dicha tradición fue recuperada (y continuada hasta el presente) por una pléyade de historiadores y antropólogos sociales que, entre otros avances, han suscitado la conformación de agendas asociadas con el estudio del indigenismo y la marginalidad en la cual se siguen moviendo enormes cúmulos de comunidades dentro del país. Este último aspecto es particularmente abordado en el texto de Andrés Medina Hernández, el cual también se puede vincular con el ejercicio emprendido por Salvador Álvarez, quien se centra en recuperar las condiciones que dieron paso a las primeras investigaciones geográficas y demográficas del territorio, sobre todo a partir de la estabilidad desencadenada durante la época del dictador Porfirio Díaz a finales del siglo XIX e inicios del XX.

Por otra parte, la contribución de Alfredo Ávila está dirigida al estudio de los primeros pensadores sociales que tuvieron influencia en el surgimiento de la idea de nación, la cual acompañaría la formación del Estado mexicano. El trabajo de Ávila da cuanta de la construcción de una nación que se movía entre los dilemas asociados con el monarquismo y el republicanismo, los modelos federal y centralista, y las diferencias existentes entre las ideologías liberal y conservadora, las cuales marcaron un hito importante para la secularización del propio Estado que, por tanto, se ubicó en una posición de supremacía frente los cacicazgos locales y el poder eclesiástico.

Dichos dilemas fundacionales heredados del turbulento siglo XIX son objeto, a su vez, de un análisis puntual por parte de Aurora Gómez Galvarriato. Esta reconstrucción se realiza de cara a las condiciones que se dieron como consecuencia del movimiento revolucionario popular surgido en la primera década del siglo XX, mismo que se vio obligado a "reconstruir" el espacio nacional mediante la acción redistributiva que diera, voz, por vez pri- mera, a los sectores más pobres de la sociedad como lo eran las masas campesinas y los sectores pobres urbanos- impulsados por los intelectuales y maestros que precisamente habían emergido en el marco de la paz dictatorial.

En su contribución específica al volumen, Cristina Puga aporta una reflexión vinculada con lo que los especialistas denominan, en el marco de las ciencias sociales mexicanas, el periodo del nacimiento y desarrollo de la modernidad, el cual abarca las décadas de 1920 a 1960, con la presencia de las primeras escuelas e institutos de carácter especializado en espacios como la UNAM, la Casa de España (hoy vigente como El Colegio de México) y la ENAH. Asimismo, es el periodo en el que surgen las primeras editoriales y revistas de corte especializado en el país, y se destaca, además, el papel de quienes se pueden catalogar como los primeros empresarios y líderes intelectuales; por ejemplo, los hermanos Antonio y Alfonso Caso, Alfonso Reyes, Daniel Cosío Villegas, Jesús Silva-Herzog o Vicente Lombardo Toledano, mismos que tuvieron la capacidad de tener apoyo y respuesta por parte de un conjunto de funcionarios públicos (e igualmente intelectuales) como Eduardo Villaseñor, Manuel Gómez Morin o Gonzalo Robles. El recorrido cubierto por este trabajo es una condensación valiosa que permite comprender la coexistencia de las primeras generaciones de pensadores del México posrevolucionario, y cómo estas pudieron coexistir con el desarrollo internacional de las propias ciencias sociales: poder salir y estudiar en el exterior apoyados con becas del Estado mexicano; o bien, interactuar y aprender con los exiliados europeos que escapaban al fascismo, el totalitarismo y la Segunda Guerra Mundial, o con los pensadores sudamericanos que arribarían al país entre los años sesenta y setenta.

Teniendo este marco introductorio, se da paso a diversas exploraciones que permiten comprender las condiciones de desarrollo experimentadas por varios sectores; específicamente, en los gremios de los economistas (María Eugenia Romero Sotelo), los juristas (José Ramón Cossío) y en el campo de la administración / política pública (Mauricio Merino). En los tres apartados se puede argumentar la existencia de una interconexión a partir del trazado de una narrativa que intenta, primero, dilucidar las condiciones particulares que dan pie a la conformación de sus respectivas comunidades, sus agendas de investigación, y, segundo, resaltar la contribu- 
ción de los personajes que mejor han representado dichos gremios.

Seguidamente, se arriba a lo que puede considerarse como una última gran sección del libro: la revisión de agendas temáticas específicas en las cuales, el papel de las ciencias sociales ha generado interrogantes y respuestas relevantes para las necesidades nacionales y del gobierno. Se observan las reflexiones abiertas por la llamada "transitología" -expresión rescatada por José Antonio Aguilar Rivera para referir al proceso de rediseño institucional de corte democratizador y liberalizador con que se dio el relevo del llamado régimen autoritario en México-, para así dar paso a la etapa actual de los dilemas que la naciente democracia política ha detonado dentro del propio Estado y sus relaciones con la sociedad. Esta situación remite, a su vez, a reconocer que dichos cambios no han tenido una respuesta sustancial dentro de las élites, las mismas que siguen siendo incapaces de adoptar en forma coherente los hábitos y las exigencias que demanda un esquema de dichas características.

De ahí que, problemáticas como la analizada por Néstor Arteaga en torno a la inseguridad y el crimen, o por Agustín Escobar Latapí con respecto a la desigualdad, exclusión y pobreza, muestran que las adaptaciones o adopciones de nuevos esquemas organizativos pasan indefectiblemente por la necesidad de poseer no solo excelentes modelos de referencia, sino modelos que también demanden cuestiones sustantivas, como las de generar sistemas informativos, de intervención y gestión, así como procesos de observación para tendencias de largo trazo. A partir de ello, se esperaría impactar adecuadamente en la erradicación de los efectos nocivos provocados por la implementación de políticas económicas que han estado acompañadas por el abandono del Estado y de una corrupción rampante.

Por último, el volumen cierra con dos trabajos que se remiten a revisar la acción reciente del Estado mexicano en lo relativo a la promoción y desarrollo de la llamada "política científica" promovida desde las dependencias administrativas asociadas a dicho campo. Tanto Gabriela Dutrénit como Oscar F. Contreras apuntan rhacia el hecho de que se puede identificar un proceso caracterizado por el esfuerzo y exigencia de una oferta naciente de las ciencias sociales por ser atendidas y apoyadas por el Estado (1930-1980), para pasar a un involucramiento puntual de demandas que comenzaron a ser impulsadas a partir de 1970 con la creación del Consejo Nacional de Ciencia y Tecnología (CONACYT). Este gesto permitió ir articulando acciones de formación, retorno y consolidación del aparato de docencia e investigación precisamente con el nacimiento del Sistema Nacional de Investigadores (SNI) -ocurrido entre los años 1980 y 2000 como un proceso de expansión- a pesar de las dificultades mostradas por la dinámica de cambios políticos y económicos, mismos que han llegado al momento presente a manifestarse en lo que concretamente Oscar F. Contreras llama la etapa de la "alianza inestable". El nombre de esta etapa se adjudica por cuanto las acciones de los gobiernos recientes han sido poco claras con respecto a mantener líneas de continuidad que permitan no solo sostener los patrones desarrollados, sino recibir mayores apoyos que permitan ofrecer avances en terrenos sustantivos, como lo implica hacer investigación aplicada de calidad que tenga incidencia e impacto para el propio Estado, y no solo pensar que las ciencias sociales implican programas de escaso valor agregado en términos de beneficio y utilidad.

En síntesis, el valor del presente libro se resume en la importancia que implica abrir ejercicios similares a lo largo y ancho de la región latinoamericana, con los cuales se puedan realizar diagnósticos fiables y comparables de dichas experiencias, a efecto de alentar la suma de esfuerzos que permitan socializar las preocupaciones con que nuestras disciplinas deben ser capaces de afrontar entornos sociales, económicos y políticos cada vez más complejos. Es por ello, que la necesidad por crear un "cuerpo de destino", como lo pensó el eminente sociólogo exiliado español José Medina Echavarría, habla con propiedad de la enorme tarea común que las disciplinas sociales tienen para responder a las ingentes urgencias que provocan las injusticias y el atraso existentes en nuestra América Latina. 
